hill, and whirling the thermometer, to read it at intervals until the bottom was reached. A return trip was then begun, and the temperature obtained again at the top of the hill. Later, minimum thermometers were similarly exposed at both places, and their readings compared. Early on clear mornings, and at night. the temperature was usually found several degrees lower in the valley, and differences of ten degrees were not uncommon. At 7 A.M. on the morning of Feb. 18, the temperature at the observatory was $3 \frac{1}{2}^{\circ}$ below zero. On descending the hill, the thermometer fell rapidly, and at the bottom of the valley read $18^{\circ}$ below zero. The fall was greatest along the steepest decline, and in one place fell three degrees within twenty-five feet. Returning, the thermometer rose rapidly, and at the top of the hill again read $32^{\circ}$ below zero.

During the continuance of these observations, Professors Pettee and Schaeberle kindly consented to take simultaneous observations of temperature with those at the observatory. One lived about a mile to the south-west, and the other about the same distance to the west. Professor Pettee was at about the same level as the observatory. and his readings differed but little from the observatory readings; but the observations taken at the home of Professor Schaeberle, which was at a considerably lower level, several times gave temperatures ten degrees lower than those at the observatory. These lower temperatures, observed both in the adjacent valley and at the home of Professor Schaeberle, were only found at night and on clear, quiet mornings, and disappeared in the middle of the day and in cloudy weather. They were due, no doubt, to the fact that the air most cooled by radiation, or by contact with the earth's surface thus cooled, was heaviest, and sunk to the lowest levels. In the middle of the day the temperature was usually found slightly higher in the valley than at the observatory.

It seems evident, then, that for scientific purposes which are intended for the study of temperature changes over large sections of country, and where stations can only be obtained many miles apart, it is necessary to avoid these merely local differences of temperature; and the only method of eliminating them is to get above them : in other words, wherever irregularities in the earth's surface exist, the thermometer should be on, or at least as high as, that of any considerable portion of land surrounding it, and not in valleys. The thermometer should, if possible, be away from buildings, and as many feet above ground as convenient. The best form of shelter is probably that devised and described by Professor Hazen. I have found by comparison that thermometers placed in accordance with these considerations differ but little in their readings though they are many miles apart in a horizontal direction. But scientific people should not fall into the error of supposing that thermometers so placed represent the temperature over the adjacent country. The position is merely that in which local influences are attempted to be avoided; and it is not safe to say to persons that their observations must be erroneous because they differ from those of the signal service or some observatory.

This is a subject I think well worthy of the consideration of those in charge of state weather services.

H. Hfrm Clayton.

Blue Hill observatory

Readville, Mass., April 16

\section{Double vision.}

Since my earliest boyhood, or for more than fifty years, I have had double vision and stereoscopic eyes, which I have probably exercised more than a million times. I have exercised the double vision to such an extent that it has become to a certain degree compulsory, as, if I look at an object forty feet more or less distant, all intervening objects are doubled involuntarily.

I often stereoscope (if that be a good verb) wallpapers and carpets, if figures be of proper size, arrangement, and distance. This has a wonderful effect, producing the following changes: the walls of an ordinary room are apparently thrown to a distance of a hundred feet, and are proportionately increased in size. Any defects in the putting-on of the paper will exhibit themselves in the same manner as I shall mention when describing the effects on gratings or lattice-work. The borders of the paper, if not 'stereoscoped' at the same time, with all pictures, etc., on the walls, will remain at their proper distances, and seem suspended in the air, like Mohammed's coffin. The surface of the paper is also remarkably increased in brilliancy. In 'stereoscoping' common photographs, they are thrown to a much greater distance, and the proper stereoscopic effect is brought about in the middle one of the three. I suppose this accounts for the increased size of the walls of rooms when so treated.

What has bothered me the most is the effect on gratings and lattice-work. In a piece of latticework, say, eight by ten feet, and the eyes five feet distant, the work is broken up, and has, instead of a common surface, an apparent depth of three or four feet. In some places there will be but a single piece; in other places two or three will be together with their parallelism properly preserved. I suppose that it is brought about by irregularities in the construction of the diagonals in the structure ; but I do not know enough about optics to explain this peculiar breaking-up, and differences in apparent distances of the different pieces making up the work. The same effects are produced in looking down at gratings in pavements. GEo. KelLer, M.D.

Bucyrus, O., May 10.

\section{Partition of Patagonia.}

The geographical note on the "Partition of Patagonia' in the current issue of Science (No. 170) calls to mind your recent strictures on cartographers for failing to keep our school maps up to the times. It would be but fair to state that the cartographers are not delinquent in this instance. The treaty of partition was concluded at Buenos Ayres, July 23, 1881, - five years ago. For the last three years all our more popular school geographies have shown the boundaries of Chili and the Argentine Republic as determined by this treaty. Russell Hinman.

Cincinnati, May 10.

\section{An old-time salt-storm.}

Can any of your readers tell me the exact date of the so-called 'salt-storm' which came upon the coast of Massachusetts about 1815? As described by old inhabitants, there was a high wind and heavy rain, and the houses and all objects within a mile of the water were coated with salt. Are such storms of frequent occurrence, and what is their explanation?

Salem, Mass., May 10. 